\title{
Toxicity study of Chlorella vulgaris water extract on female Sprague Dawley rats by using the Organization for Economic Cooperation and Development (OECD) Guideline 420
}

\author{
Nurhazirah Zainul Azlan ${ }^{1,2}$ (D) $\cdot$ Norzana Abd Ghafar $^{3} \cdot$ Yasmin Anum Mohd Yusof $^{4}$ (D) Suzana Makpol ${ }^{1}$ (D)
}

Received: 28 February 2020 / Revised and accepted: 9 June 2020 / Published online: 15 July 2020

(C) The Author(s) 2020

\begin{abstract}
Chlorella vulgaris, a coccoid green eukaryotic microalga, is a popular food supplement and has been marketed as a nutritional supplement in Asia. Despite numerous reports on the antioxidant property of this species, its toxic effect has not been extensively studied. The aim of this study was to determine the acute oral toxic effect of $C$. vulgaris on female Sprague Dawley (SD) rats. An acute oral toxicity assessment of $C$. vulgaris was performed based on the Organization for Economic Cooperation and Development (OECD) Guideline 420. These guidelines are divided into a sighting study and a main study. In the sighting study, C. vulgaris extract was administered orally in sequential doses of 5, 50, 300 and $2000 \mathrm{mg} \mathrm{kg}^{-1}$ body weight (BW) with one rat used for each dosage. Clinical observation and mortality were observed for each rat to monitor signs of toxicity for 14 days. BW and relative organ weight (ROW) were recorded. Blood was collected for liver function test (LFT). Gross pathological evaluations were performed after euthanasia of rats. Haematoxylin and eosin (H\&E) staining of the liver and kidney was also performed. The main study was performed based on the highest dose in the sighting study that did not exhibit any signs of toxicity and mortality. For 14 days, clinical observations, BW, and ROW were recorded. Blood from rats in the main study was also measured for LFT, and gross pathological evaluations and H\&E staining of the liver and kidney were also performed. The highest dose of $2000 \mathrm{mg} \mathrm{kg}^{-1} \mathrm{BW}$ C. vulgaris was used in the main study. No toxicity and mortality were observed in both the sighting study and the main study. Increases in BW were observed in both studies. Gross pathological evaluations showed no signs of organ abnormalities on each organ in the sighting and main studies. The ROW also showed no differences. The values of biochemical parameters in the liver function test showed no differences in the sighting study. However, in the main study, significant decreases in alkaline phosphatase (ALP) and aspartate aminotransferase (AST) were observed on day 14 compared with day $0(p<0.05)$. Chlorella vulgaris showed no toxicity at the dose of $2000 \mathrm{mg} \mathrm{kg}^{-1} \mathrm{BW}$. In conclusion, $C$. vulgaris can be categorized as unclassified according to the Globally Harmonised Classification System (GHS) for chemical substances and mixtures.
\end{abstract}

Keywords Chlorella vulgaris $\cdot$ Chlorophyta $\cdot$ Antioxidant $\cdot$ Acute oral toxicity $\cdot$ Hepatotoxic $\cdot$ OECD Guideline 420

Suzana Makpol

suzanamakpol@ppukm.ukm.edu.my

Nurhazirah Zainul Azlan

nurhazirah@iium.edu.my

Norzana Abd Ghafar

norzana@ukm.edu.my

Yasmin Anum Mohd Yusof

rahmatyasmin@yahoo.com

1 Department of Biochemistry, Faculty of Medicine, Level 17, Preclinical Building, Universiti Kebangsaan Malaysia Medical Centre, Jalan Yaacob Latif, Bandar Tun Razak, Cheras, 56000 Kuala Lumpur, Malaysia
2 Department of Basic Medical Sciences for Nursing, Kulliyyah of Nursing, International Islamic University Malaysia, P. O. Box 141, 25710 Kuantan, Pahang, Malaysia

3 Department of Anatomy, Faculty of Medicine, Level 18, Preclinical Building, Universiti Kebangsaan Malaysia Medical Centre, Jalan Yaacob Latif, Bandar Tun Razak, Cheras, 56000 Kuala Lumpur, Malaysia

4 Faculty of Medicine and Defense Health, Universiti Pertahanan Nasional Malaysia, Kem Sungai Besi, 57000 Kuala Lumpur, Malaysia 


\section{Introduction}

Microalgae have been consumed for thousands of years in the human diet due to their high protein content and various bioactive components, which are responsible for their anticarcinogenic, antioxidative and antihypertensive properties (Koyande et al. 2019). Microalgae are eukaryotic photosynthetic microorganisms that can grow rapidly and can produce proteins, lipids and carbohydrates in a large scale over short periods of time (Brennan and Owende 2010; Lordan et al. 2011). Examples of widely used microalgae species include Arthrospira (Spirulina) platensis, Chlorella spp. and Dunaliella salina (Garcia et al. 2017).

The phylum Chlorophyta, also known as green algae, is a large group of organisms with wide morphological variability, ranging from microscopic to macroscopic forms. They contain chlorophyll $a$ and $b$, along with different types of carotenoids (Grobbelaar 2004). Unicellular green algae of the genus Chlorella belong to the most popular photosynthetic microalgae being studied and investigated (Krienitz et al. 2015). Additionally, Chlorella has been studied in diverse applications of biotechnology; for example, Chlorella protothecoides and Chlorella sorokiniana have been studied for biodiesel production (Griffiths and Harrison 2009; Gao et al. 2010), and Chlorella fusca and C. sorokiniana have been studied for biosorption of heavy metals from wastewaters (Akhtar et al. 2003; Ahluwalia and Goyal 2007).

In this study, Chlorella vulgaris was studied for its acute oral toxicity. Chlorella has been the most cultivated eukaryotic alga due to its wide use as a commercial health food and feed supplement, as well as in the pharmaceutical and cosmetic industries and in pigments and aquaculture feed, particularly in Asia (Masojídek and Torzillo 2008; Phang 2010; Panahi et al. 2013). Chlorella vulgaris from Malaysia has been reported to display inhibition of lipid peroxidation with higher antioxidant activity compared with $\alpha$-tocopherol (Natrah et al. 2007). The antioxidant property of $C$. vulgaris was also reported in other studies (Aliahmat et al. 2012; Makpol et al. 2013). A study of the wound healing activity of $C$. vulgaris extract found that the extract exhibited pro-healing and anti-inflammatory properties, with evidence of wound healing acceleration (de Melo et al. 2019).

Previous studies have reported several pharmacological effects of $C$. vulgaris. These include anticancer activity (Azamai et al. 2009; Yusof et al. 2010; Wang et al. 2010), antidiabetic activity (Shibata et al. 2003; Jeong et al. 2009; Aizzat et al. 2010) and antihyperlipidaemic activity (EbrahimiMameghani et al. 2014; Vecina et al. 2014). In addition, previous studies have also reported that this alga has a beneficial effect for the regeneration of muscle during ageing in preventing sarcopenia in the elderly (Zainul Azlan et al. 2019a, 2019b).
Chlorella vulgaris had been reported as an alga with highly nutritive contents, such as carbohydrates, proteins, nucleic acids, vitamins and minerals (Saad et al. 2006). It has also been reported as having $\beta$-carotene, lutein, chlorophyll- $a$, chlorophyll- $b$, ascorbic acid, tocopherol, riboflavin and retinol (Kitada et al. 2009; Panahi et al. 2012). Furthermore, C. vulgaris has been reported to be beneficial as a detoxifying agent, as indicated by the significant removal of mercury deposition from the tissue of mice facilitating its excretion through faeces (Yadav et al. 2020).

Previously, it has been reported that the feeding of C. vulgaris from different types of preparation - singly spray dried, electroporated and spray dried, and ultrasonized and spray dried - for 33 days on Wistar rats did not exhibit any adverse effects on serum biochemistry, blood haematology or histological structure of organs (Janczyk et al. 2005). In another study, C. vulgaris strain CK-22 was investigated for its safety as a food supplement. No mortality and clinical signs of toxicity were observed in both single dose and 28-day oral toxicity test on Wistar rats. This algae also exhibited no mutagenicity in the in vitro assay suggesting that $C$. vulgaris is safe as a food supplement (Himuro et al. 2014). However, with the immense ongoing and future research of the pharmacological effect of $C$. vulgaris, it is beneficial to thoroughly investigate the potential hepatotoxicity of this alga.

A previous study reported that $C$. vulgaris that was locally grown had a better anticancer effect on the HepG2 liver cancer cell line compared with $C$. vulgaris from Japan (Saad et al. 2006). In addition, a recent study reported large discrepancies between the factual and declared content of mineral and toxic elements in selected $C$. vulgaris food supplements with copper $(\mathrm{Cu})$ content, finding the levels to be significantly higher (Rzymski et al. 2018). Therefore, it is important to further determine the potential hepatotoxicity imposed by C. vulgaris. This study will be the first to determine the potential toxicity of $C$. vulgaris based on the Organization for Economic Cooperation and Development (OECD) Guideline 420 (OECD 2001). Based on the results of this study, a nontoxic range of $C$. vulgaris concentrations will be established as a recommendation for dosage selection for future research.

\section{Materials and methods}

\section{Animals}

This study has been approved by the Universiti Kebangsaan Malaysia Medical Research and Innovation Secretariat (project code FF-2016-318) and the Universiti Kebangsaan Malaysia Animal Ethics Committee (UKMAEC approval number BIOC/PP/2016/SUZANA/27-JULY/770-SEPT.2016-AUG.-2018). The care and use of animals in this study were also carried out in accordance with the ethical norms 
approved by the UKMAEC guidelines for animal care. The acute toxicity study of Chlorella vulgaris was performed based on OECD Guideline 420 (OECD 2001). Based on these guidelines, the study was divided into two parts: the sighting study and the main study. Eight non-pregnant female Sprague Dawley (SD) rats, at the age of 8 to 12 weeks old and with weight between 150 and $250 \mathrm{~g}$, were used. The rats were maintained in the animal care facilities with a 12-h dark and light cycle. The rats were also kept in individual cages and left to acclimatize for 1 week prior to treatment. Wood shavings were used as the bedding of the rats, with rat pellets and water being provided at all times (ad libitum).

\section{Preparation of Chlorella vulgaris}

Stock of C. vulgaris Beijerinck (strain 072) was obtained from the University of Malaya Algae Culture Collection (UMACC, Malaysia). The stock was grown in Bold's Basal Medium (BBM) (Andersen et al. 2005) with a 12-h dark and light cycle and then harvested by centrifugation at $112 \times \mathrm{g}$ for $10 \mathrm{~min}$ at $4{ }^{\circ} \mathrm{C}$ for separation of the algae from the media (Ngah and Yusof 2006; Aliahmat et al. 2012). The algae were weighted according to each rat's body weight (BW) and diluted with $1 \mathrm{~mL}$ of distilled water prior to treatment. Treatments of C. vulgaris extract were given by gavage once and monitored for 14 days.

\section{Sighting study}

In the sighting study, four female rats were used. The main purpose of this sighting study was to select the optimum dosage to be used in the main study and to minimize the number of rats to be used. The starting dosage of $C$. vulgaris in this sighting study was $5 \mathrm{mg} \mathrm{kg}^{-1} \mathrm{BW}$ followed by 50,300 and $2000 \mathrm{mg} \mathrm{kg}^{-1} \mathrm{BW}$ sequentially, with one rat used for each dosage for 24-h intervals between dosages. The starting dose in this study actually deviated from the OECD Guideline 420. According to OECD Guideline 420, the starting dose for the sighting study was $300 \mathrm{mg} \mathrm{kg}^{-1} \mathrm{BW}$ in the absence of evident toxicity data from the same chemical or structurally related chemicals. Although C. vulgaris had no prior report of toxicity, a $5-\mathrm{mg} \mathrm{kg}^{-1} \mathrm{BW}$ dose was still chosen for affirmation as it did not cause any toxicity by examining the LFT and histology analysis at a lower dosage.

\section{Main study}

Five female SD rats were used in the main study. Four of them were new rats, and one rat was from the sighting study (the one that received the highest dose that did not cause death). From the sighting study, it was found that the highest dose of $2000 \mathrm{mg} \mathrm{kg}^{-1}$ BW C. vulgaris extract did not cause mortality and toxicity signs. Therefore, the dose of $2000 \mathrm{mg} \mathrm{kg}^{-1} \mathrm{BW}$
C. vulgaris extract was selected for the main study and was administered orally once with an interval of 3 days between each rat. The extract was freshly prepared before administration and was calculated based on the current BW of the rat.

\section{Clinical observation}

The rats were observed individually at $0.5,1,2,3$ and $4 \mathrm{~h}$ after administration of $C$. vulgaris extract. The rats were then observed after $24 \mathrm{~h}$, followed by observation twice daily thereafter for the duration of 14 days for mortality and clinical toxicity signs. The signs of clinical toxicity included changes in the skin, fur, eyes, mucous membranes, and behavioural patterns; tremors; salivation; diarrhoea; occurrence of secretion; excessive grooming; repetitive circling and bizarre behaviour such as self-mutilation and walking backwards. Throughout the experimentation, the rats were also closely monitored for any signs of pain, including excessive licking or scratching, redness and swelling at any site, anorexia as indicated by the absence of faeces, struggling, squealing, convulsions, twitching, tremors, weakness, teeth grinding, hunched up posture, unwilling to move and favouring a limb. The other signs of pain included a decrease in appetite by evidence of few faeces, biting of an affected body part, reluctance to move, increased respiration, change in bowel or urinary activities and porphyrin discharge, as evidenced by redbrown pigment around the eyes and nostrils. The body weight (BW) of each rat was recorded on days 0 (prior to dosing), 2, 4, 6, 8, 10, 12 and 14.

\section{Collection of blood}

Rats were anaesthetized prior to blood collection on days 0 and 14 by orbital sinus collection. A blood volume of $3 \mathrm{~mL}$ was collected and transferred into a plain vacuum tube for serum separation by centrifugation at $112 \times g$ for $15 \mathrm{~min}$ to obtain plasma. The plasma was then sent to the pathology laboratory to perform biochemical analysis via a liver function test (LFT). The LFT was assessed by measurements of biochemical parameters such as aspartate aminotransferase (AST), alanine aminotransferase (ALT) and alkaline phosphatase (ALP).

\section{Necropsy}

All of the rats were fasted overnight on day 14 before they were sacrificed. KTX agent, which is a combination of ketamine, xylazine and zoletil-50 (tiletamine and zolazepam), was used in this study as the anaesthesia agent. This anaesthesia agent was administered by intraperitoneal injection (i.p.) in the lower right quadrant of the abdomen based on $0.1 \mathrm{~mL}$ per $250 \mathrm{~g}$ of rat body weight. Complete and thorough gross post-mortem examinations were performed to check for the 
presence of tissue malignancy and lesions, such as abscesses, development defects and neoplasia. The organs, including the lung, heart, liver, kidneys, spleen, stomach and gastrointestinal tract (GIT), from the sacrificed rats were cleaned of any adherent tissue and washed with $90 \%$ normal saline. Each organ's weight (absolute organ weight) was taken as soon as possible to avoid drying, and the organs were kept in a container with $10 \mathrm{~mL}$ of $10 \%$ neutral formalin. These organs were analysed relative to the $\mathrm{BW}$ of the animals. The resulting data reflected the relative organ weight (ROW) in relation to $100 \mathrm{~g}$ BW of the animal, as shown in Eq. 1 below:

$$
\begin{aligned}
\text { ROW } & \left(\frac{\mathrm{g}}{100 \mathrm{~g}}\right) \\
= & (\text { Absolute organ weight }(\mathrm{g}) \div \text { Body weight }(\mathrm{g})) \\
& \times 100
\end{aligned}
$$

\section{Histology and histochemical analysis}

Liver and kidney were fixed in $10 \%$ neutral formalin to preserve the tissues permanently. The organs were cut into small sections and processed with an Automated Vacuum Tissue Processor (STP 120 Spin Tissue Processor, Thermo Fisher Scientific, USA). Then, the organs were embedded in paraffin (Surgipath Paraplast, Leica Biosystems, USA). The organs were later cut into $5-\mu \mathrm{M}$ sections and haematoxylin and eosin (H\&E) stained and mounted with DPX mountant (VWR International Ltd., England) and viewed under a dissecting BX53 microscope (Olympus, Japan).

\section{Statistical analysis}

The data are expressed as the mean $\pm \mathrm{SD}$, and a value of $p<0.05$ was considered statistically significant. Statistical analysis was carried out using SPSS software version 25 . Data were analysed using the paired-samples $t$ test.

\section{Results}

\section{Clinical observations}

No physical and behavioural changes were observed in any of the treated rats after oral administration of $C$. vulgaris for 14 consecutive days in both the sighting and main studies. No mortality was observed in either study. All the clinical observations for the sighting and main studies are recorded in Table 1.

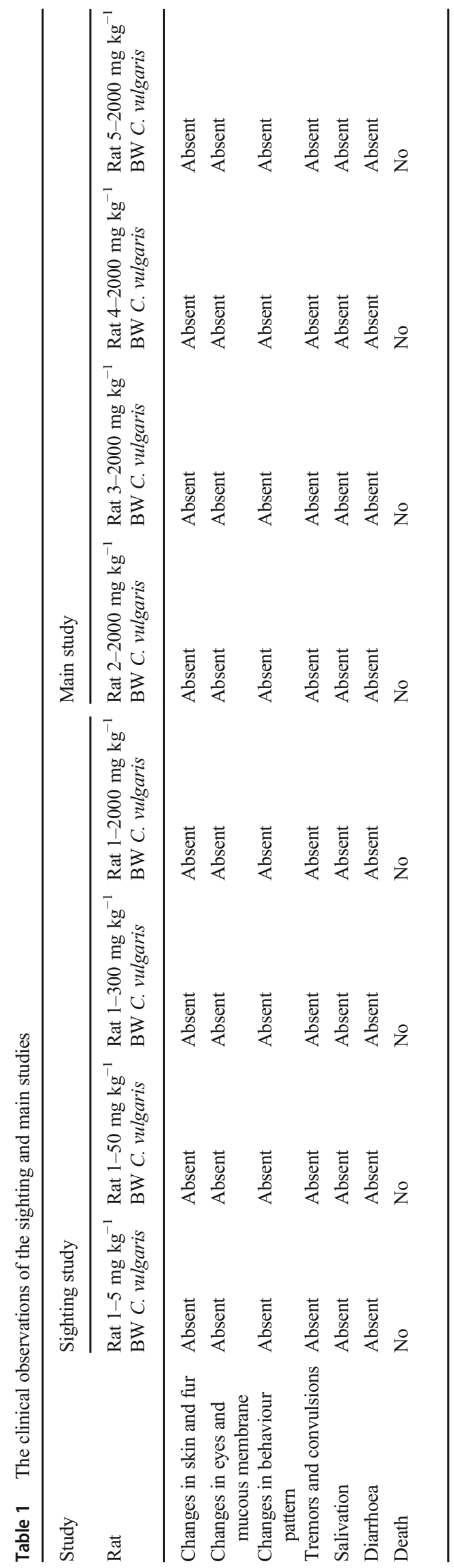




\section{Body weight}

Table 2 shows the BW of rats in the sighting and main studies. All of the rats showed increases in BW over the 14 days with more than $29 \%$ increased BW. Figure 1 shows significant increases in the mean BW of rats in the main study on days $8,10,12$ and 14 compared with the mean BW on day 0 .

\section{Necropsy}

Gross findings revealed no observation of any abnormal finding on the internal organs for each rat. No shrinkage or enlargement of organs was observed. No presence of organ malignancy, lesion, neoplasia or abscesses was observed. The ROWs for the lung, heart, spleen, kidney, liver, stomach, GIT and brain of the sighting study demonstrated no differences between the rats. The ROWs for the lung, heart, spleen, kidney, liver, stomach and brain in the main study also demonstrated no differences between the rats, except for GIT. The ROWs of the sighting and main studies are shown in Fig. 2 a and $b$, respectively.

\section{Liver function test}

The liver function test results are shown in Table 3 for the sighting and main studies on day 14 . The levels of total protein, albumin, globulin, albumin/globulin ratio, ALP, AST and ALT of each C. vulgaris-treated rat exhibited similar values of biochemical parameters. Figure 3 shows the liver function test results of rats in the main study between day 0 and day 14 . There was no significant difference between day 0 and day 14 for total protein, albumin, globulin, albumin/ globulin ratio and ALT. However, there was a significant decrease on day 14 for ALP and AST compared with day 0 $(p<0.05)$.

\section{Histology and histochemical analysis}

Figure 4 shows the photomicrographs of H\&E staining of the liver, while Fig. 5 shows the photomicrographs of H\&E staining of the kidneys of rats treated with $C$. vulgaris for 14 days in the sighting and main studies. The livers of all treated rat with $C$. vulgaris showed normal liver architecture with radiating hepatocyte cords from the central vein and normal sinusoidal spaces. There was no evidence of hepatocellular necrosis, inflammatory infiltrate and macrovesicular steatosis. The kidneys of all treated rats with $C$. vulgaris showed no signs of interstitial inflammatory infiltrate, tubular atrophy, interstitial fibrosis or acute tubular necrosis.

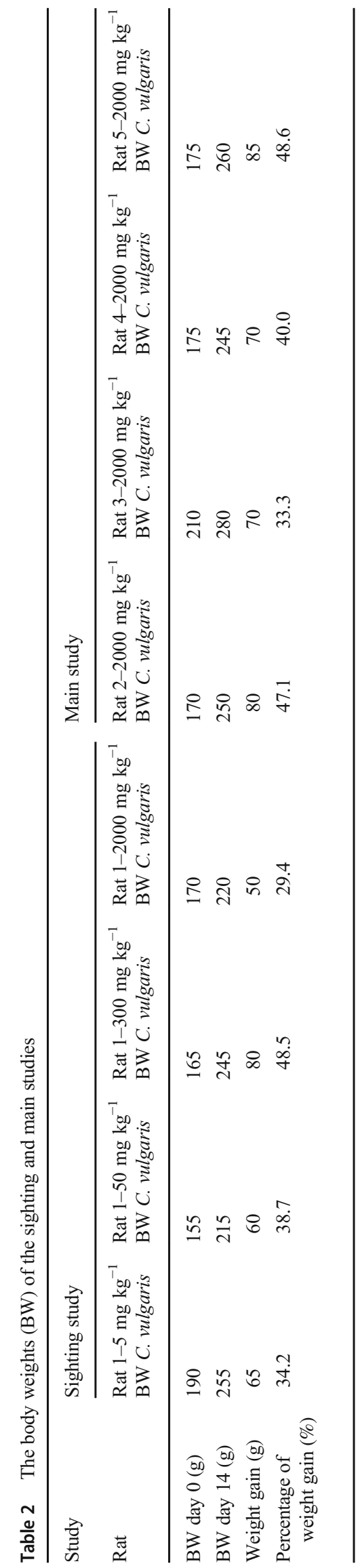


Fig. 1 The mean body weight (BW) of rats in the main study increased significantly on days 8 ,

10,12 and 14 after single-dose administration of $2000 \mathrm{mg} \mathrm{kg}^{-1}$ BW C. vulgaris. The data are presented as the means $\pm \mathrm{SD}$, $n=5 . * p<0.05$ indicated a significant difference compared with day 0 , with paired-samples $t$ test

Fig. 2 The relative organ weight (ROW) of rats in the sighting (a) and main studies (b), treated with a single oral dose of $C$. vulgaris extract ( $\mathrm{mg} \mathrm{kg}^{-1} \mathrm{BW}$ ), showed no significant differences
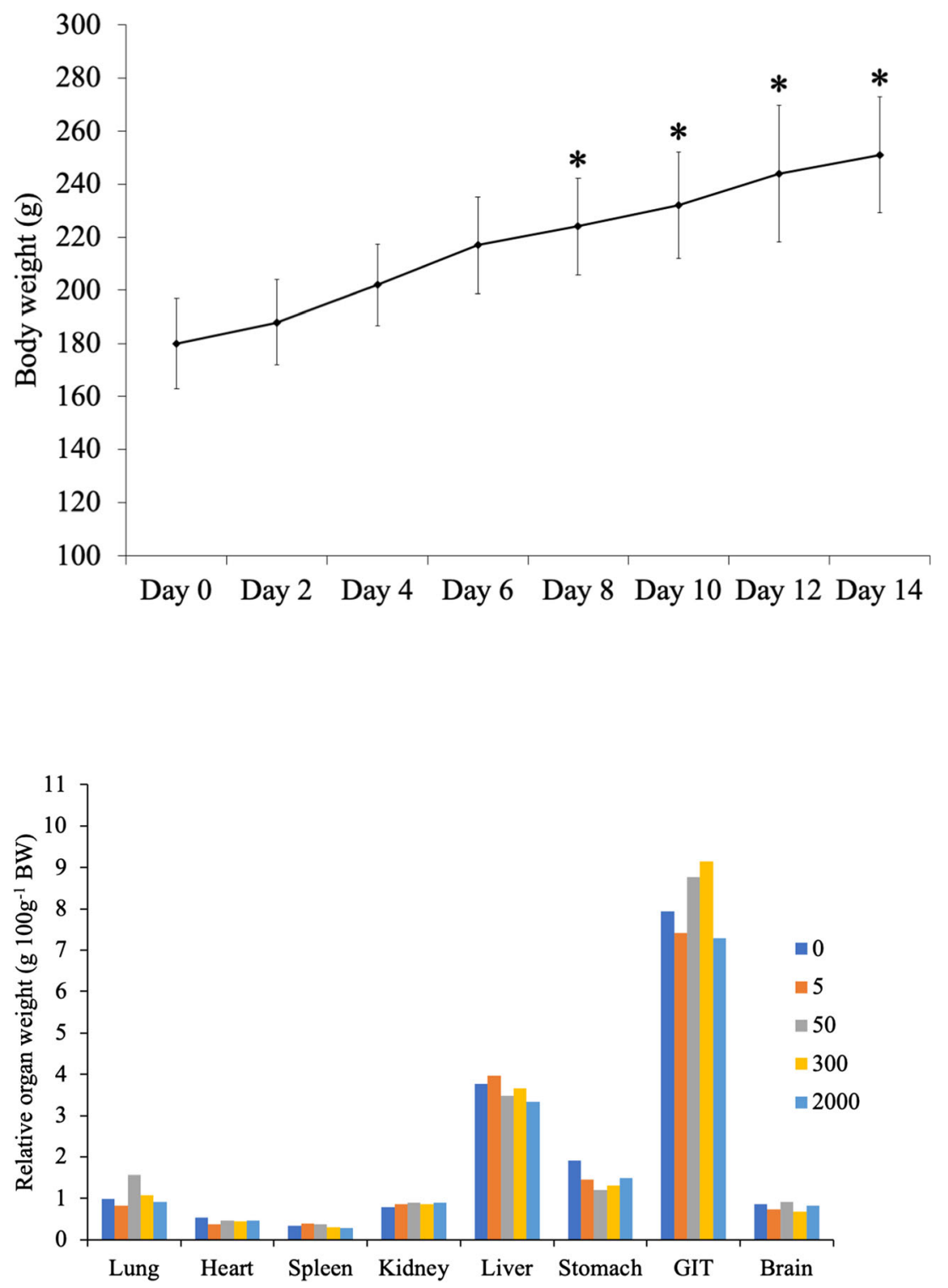

(a)

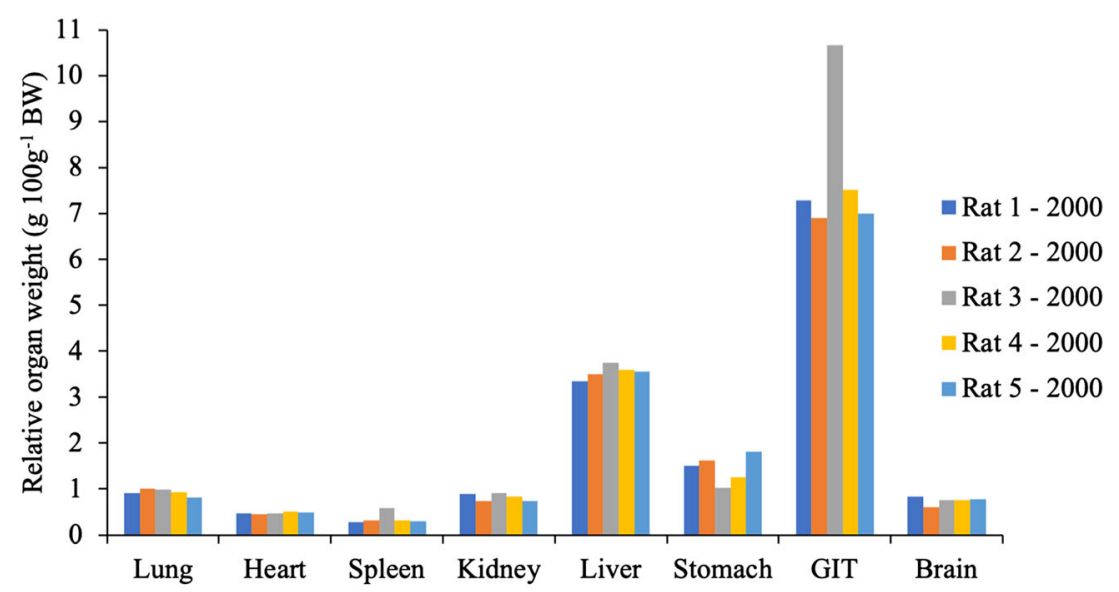

(b) 


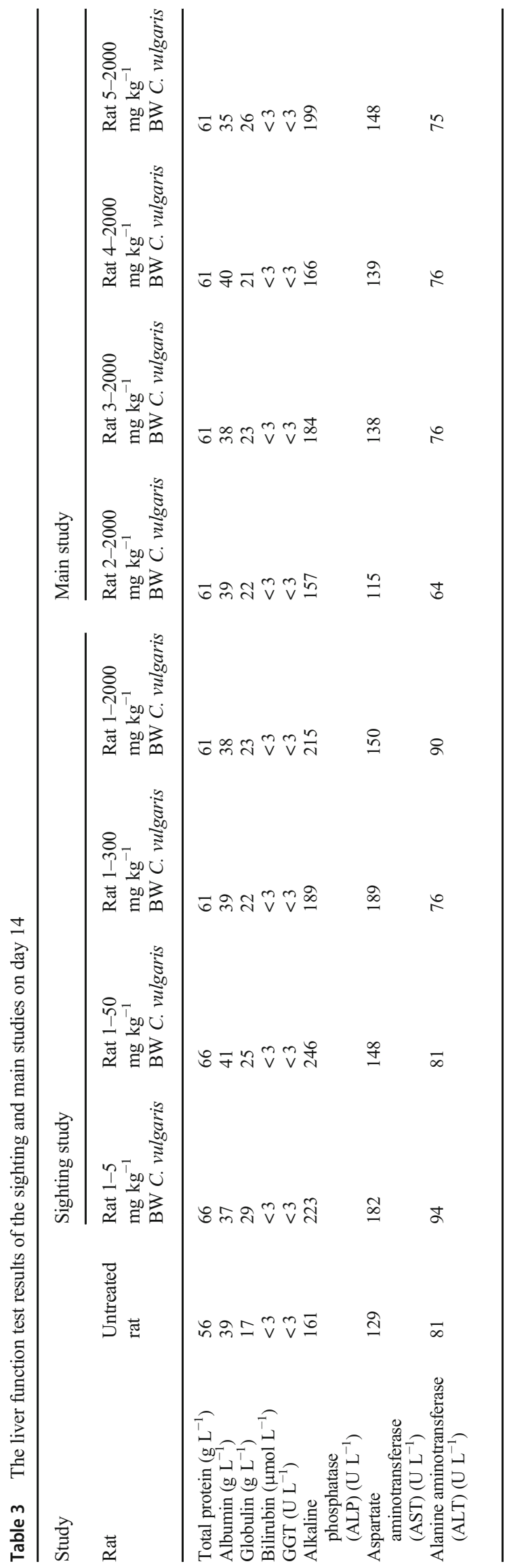

\section{Discussion}

The differences in BW may be impacted by several factors, including changes in growth, as seen in alterations in growth hormone or somatostatin, alterations of hormonal status that can be seen in the secretion of sex steroids that can change maturational patterns and alterations in neurotransmitters that can affect the consumption of food (Bailey et al. 2004). Moreover, the environment of the rats can also cause stress to the rats and result in BW changes. The type of treatment can also cause BW differences. However, in this study, increased BW was observed in all rats with more than $29 \%$ increases in BW in day 14 compared with day 0 . Therefore, the increased BW observed demonstrated the normal growth of each rat, with no indication of toxicity.

Changes in organ weight have been practically used as a sensitive indicator of chemically induced changes towards organs. It is a conventional method to compare organ weights between groups of animals to elucidate the toxic effect of an extract. The weight of the liver has been cited as the most vital in toxicity studies because of its sensitivity to predict toxicity, which is practical in evaluating hepatocellular status, as there is a minimal animal-to-animal variability (Michael et al. 2007). However, with the highest dosage of $2000 \mathrm{mg} \mathrm{kg}^{-1}$ BW C. vulgaris, the ROW of each organ exhibited no significant differences, and no malignancies or abnormalities were observed on the organs of each rat treated with $C$. vulgaris. Therefore, this finding may suggest that administration of C. vulgaris resulted in no toxicity.

The biochemical parameters of the liver function test are not specific to the liver and are also not true measures of liver function, as they may reflect problems arising from outside the liver (Johnston 1999; Boyer et al. 2012). This test is usually used for the detection of liver disease, the possible underlying cause, severity estimation, prognosis assessment and observing the efficacy or toxicity of a therapy. Any abnormalities demonstrated in the liver function test could be an indication of subclinical liver disease; hence, further diagnostic evaluation can proceed (Boyer et al. 2012). This test is also advantageous in ascertaining the area of hepatic injury, and the elevation pattern can also help to determine a list for differential diagnosis (Lala et al. 2020).

The normal ranges in the LFT for SD rats age 7 to 11 weeks old are 45 to $84 \mathrm{~g} \mathrm{~L}^{-1}$ for total protein, 40 to $48 \mathrm{~g} \mathrm{~L}^{-1}$ for albumin, 12 to $20 \mathrm{~g} \mathrm{~L}^{-1}$ for globulin, 1.2 to $2.0 \mu \mathrm{mol} \mathrm{L}^{-1}$ for bilirubin, 132 to $312 \mathrm{U} \mathrm{L}^{-1}$ for ALP, 0 to $3 \mathrm{U} \mathrm{L}^{-1}$ for gammaglutamyl transferase (GGT), 77 to $157 \mathrm{U} \mathrm{L}^{-1}$ for AST and 22 to $224 \mathrm{U} \mathrm{L}^{-1}$ for ALT (Sharp and La Regina 1998; Suckow et al. 2006). In this study, the total protein, bilirubin, ALP, GGT and ALT were observed to be in the normal ranges in both the sighting and main studies. However, in the sighting study, the level of albumin was below the normal range, the globulin level was higher than the normal range in rats treated 


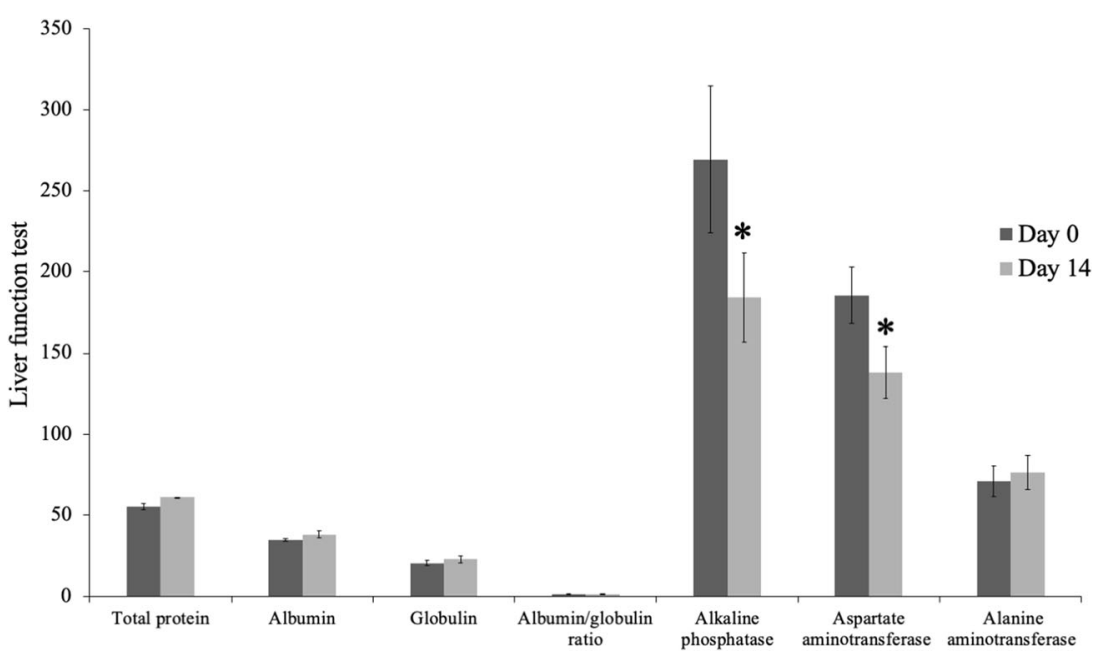

Fig. 3 Liver function test results of rats in the main study between day 0 and day 14 with a single treatment dose of $2000 \mathrm{mg} \mathrm{kg}^{-1} \mathrm{BW}$ C. vulgaris demonstrated significant decreases in ALP and AST after 14 days of administration. The data are presented as the means $\pm \mathrm{SD}, n=5$.
$* p<0.05$ indicated a significant difference compared with day 0 , with paired-samples $t$ test. Total protein, albumin and globulin in $\mathrm{g} \mathrm{L}^{-1}$; ALP, AST and ALT in $\mathrm{U} \mathrm{L}^{-1}$. with 50,300 and $2000 \mathrm{mg} \mathrm{kg}^{-1} \mathrm{BW}$ of $C$. vulgaris and the AST level was higher than the normal range in rats treated with 50 and $300 \mathrm{mg} \mathrm{kg}^{-1} \mathrm{BW}$ of $C$. vulgaris. The same results were observed in the main study, with the level of albumin below the normal range and the level of globulin higher than the normal range.

The lower level of albumin observed might be caused by malnutrition due to poor protein intake and protein loss, such as in malabsorption, nephrotic syndrome or protein-losing enteropathy (Boyer et al. 2012; Lala et al. 2020). Albumin synthesis may also be affected by nutritional status, hormonal balance and osmotic pressure (Boyer et al. 2012). A globulin level that is higher than the normal range can result from adrenal insufficiency, hypothyroidism, nephrotic syndrome, cirrhosis and certain types of cancer. However, the determination of different types of globulins can further narrow down the causes of its elevation (O'Connel et al. 2005). The AST enzyme can be found in various tissues, such as the liver, heart, skeletal muscle, kidney, brain, pancreas, lungs, leukocytes and erythrocytes. This enzyme is commonly elevated in cardiac and muscle disease. Mild elevations of AST can also be seen in fatty liver, chronic hepatitis and non-alcoholic steatohepatitis; moderate elevations of AST might be due to acute or chronic hepatitis; and high elevations of AST can be induced by severe viral hepatitis, drug- or toxin-induced hepatic necrosis and circulatory shock (Boyer et al. 2012). The AST enzyme is also not as sensitive or specific to the liver, and its elevations may also be observed as secondary to nonhepatic causes (Lala et al. 2020). Moreover, as shown in Table 3, there was no dose-response relationship, and it was not possible to draw a conclusion from the data, as only one rat was administered per dosage. Nevertheless, no remarkable changes were observed in relative liver weight, and histology showed no evidence of malignant hepatic lesions, hepatocellular necrosis, inflammatory infiltrate and macrovesicular steatosis in the liver of each rat.

The biochemical parameter markers for liver toxicity are ALT and GGT, as they are found predominantly in the liver, thus making them liver-specific and the first abnormal liver function tests demonstrated in liver toxicity. Increases in the plasma levels of both ALT and AST also indicate liver toxicity due to the leakage of damage or necrotic cells with ALT levels higher than AST levels. Although GGT is found in the greatest concentration in the kidney, it is also useful in the diagnosis of liver toxicity, as it is the most sensitive test for detecting liver toxicity. The GGT test is highly accurate in detecting liver dysfunction, and the elevation of GGT level is correlated with elevations of ALP level in liver toxicity (Chatterjea and Chawla 2010; Pagana and Pagana 2010; Bishop et al. 2013). The result obtained from this study did not show any increase in ALT and GGT levels; thus, no liver toxicity was observed. These findings were further proven by no observable changes in relative liver weight and no abnormal findings on the histopathology of the liver in each rat treated with different dosages of $C$. vulgaris.

Based on the observation from the sighting and main studies of acute oral toxicity of $C$. vulgaris extract, it can be deduced that a single-dose oral administration of $C$. vulgaris at $2000 \mathrm{mg} \mathrm{kg}^{-1} \mathrm{BW}$ did not cause acute hepatotoxicity in SD rats (Fig. 6). These findings are supported by the lack of physical and behavioural changes, mortality or any significant differences in BW, ROW and biochemical parameters in the liver 
Fig. 4 Microscopic liver findings of rats treated with $C$. vulgaris in the sighting and main studies, with no evidence of toxicity, such as inflammation, necrosis and apoptosis $(\mathrm{H} \& \mathrm{E} \times 50)$

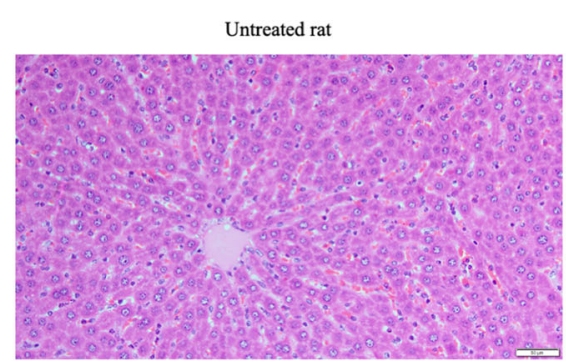

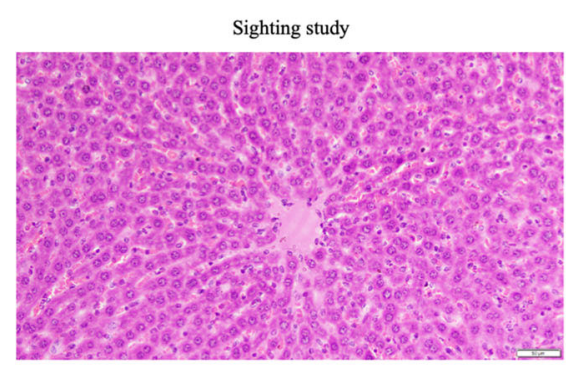

Rat 1 - $5 \mathrm{mg} \mathrm{kg}^{-1} \mathrm{BW}$ C. vulgaris

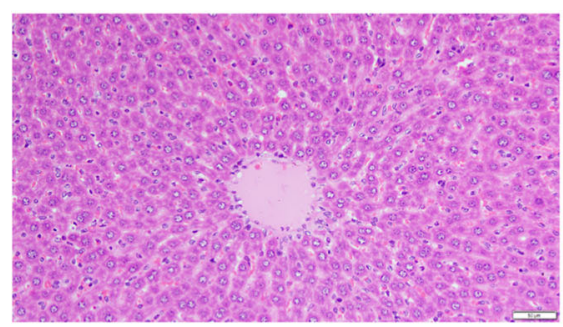

Rat 1 - $50 \mathrm{mg} \mathrm{kg}^{-1} \mathrm{BW}$ C. vulgaris

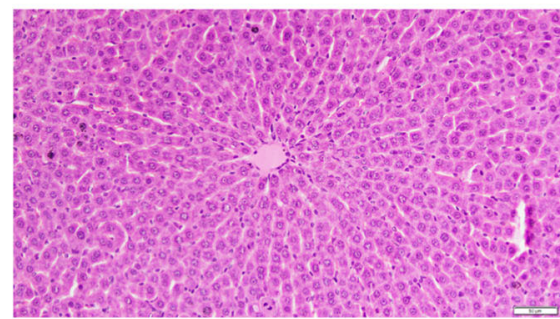

Rat 1 - $300 \mathrm{mg} \mathrm{kg}^{-1} \mathrm{BW}$ C. vulgaris

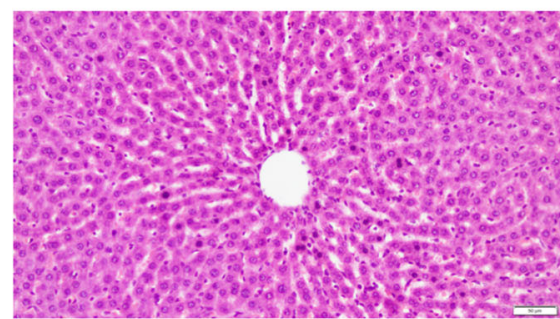

Rat 1 - $2000 \mathrm{mg} \mathrm{kg}^{-1} \mathrm{BW}$ C. vulgaris

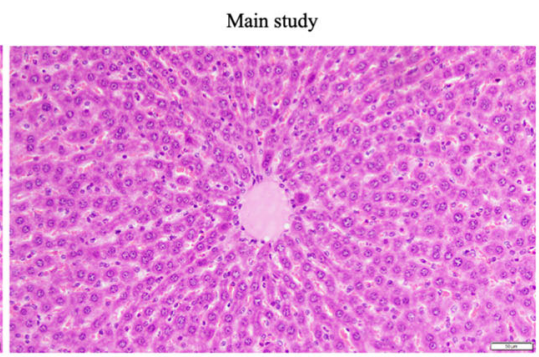

Rat $2-2000 \mathrm{mg} \mathrm{kg}^{-1} \mathrm{BW}$ C. vulgaris

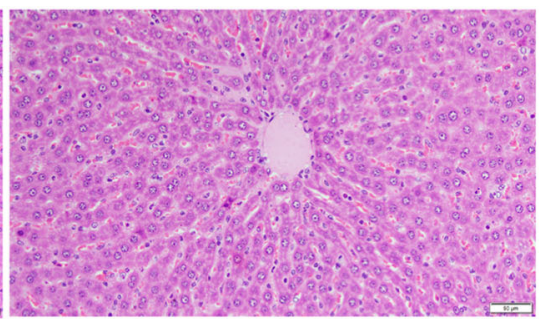

Rat 3 - $2000 \mathrm{mg} \mathrm{kg}^{-1} \mathrm{BW}$ C. vulgaris

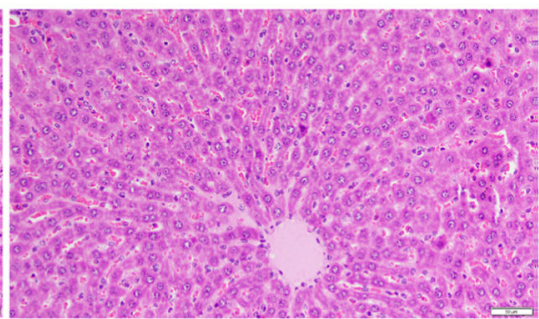

Rat $4-2000 \mathrm{mg} \mathrm{kg}^{-1} \mathrm{BW}$ C. vulgaris

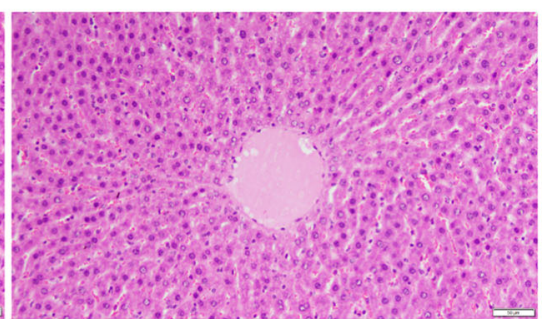

Rat 5 - $2000 \mathrm{mg} \mathrm{kg}^{-1} \mathrm{BW}$ C. vulgaris function test. Therefore, C. vulgaris can be categorized as unclassified based on the GHS classification. Based on the OECD Guideline 420, a test item with no evidence of toxicity up to $2000 \mathrm{mg} \mathrm{kg}^{-1} \mathrm{BW}$ in the main study can be categorized as category 5 or unclassified under the GHS category. Category 5 under the GHS classification is the identification of a test item with relatively low acute toxicity but which, under certain conditions, may result in threat (OECD 2001a,
$2001 b)$. However, with no evidence of toxicity with $2000 \mathrm{mg} \mathrm{kg}^{-1} \mathrm{BW}$ of $C$. vulgaris, this microalga can be categorized as unclassified under GHS classification due to the lack of any specific target organ or systemic toxicity observed.

A previous study on $C$. vulgaris strain CK-22 has reported the $\mathrm{LD}_{50}$ of this alga to be more than $5000 \mathrm{mg} \mathrm{kg}^{-1}$ BW (Himuro et al. 2014). In another study, the intake of carotenogenic of $C$. vulgaris did not demonstrate any 
Fig. 5 Microscopic kidney findings of rats treated with C. vulgaris in the sighting and main studies, with no evidence of toxicity, such as inflammation, necrosis and apoptosis $(\mathrm{H} \& \mathrm{E} \times 50)$
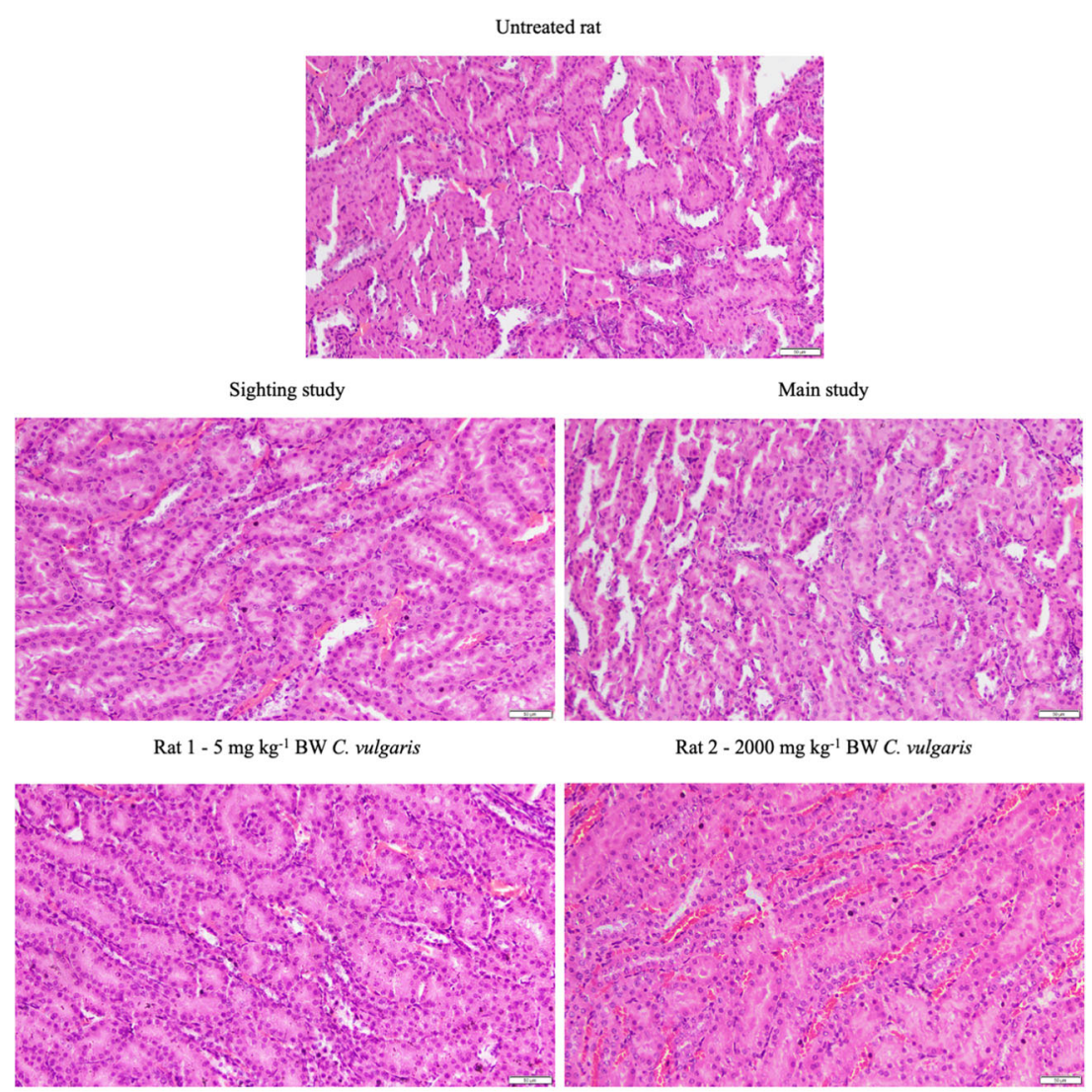

Rat $1-50 \mathrm{mg} \mathrm{kg}^{-1} \mathrm{BW}$ C. vulgaris

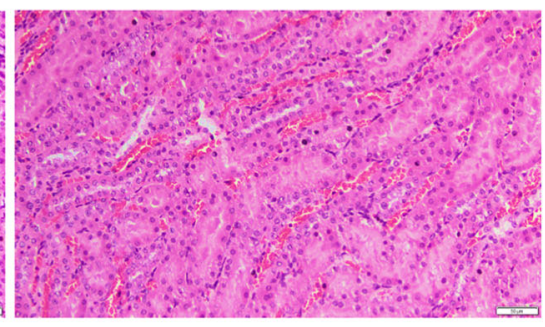

Rat 3 - $2000 \mathrm{mg} \mathrm{kg}^{-1} \mathrm{BW}$ C. vulgaris

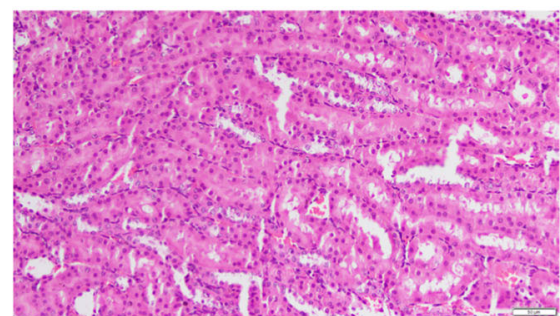

Rat $1-300 \mathrm{mg} \mathrm{kg}^{-1} \mathrm{BW}$ C. vulgaris

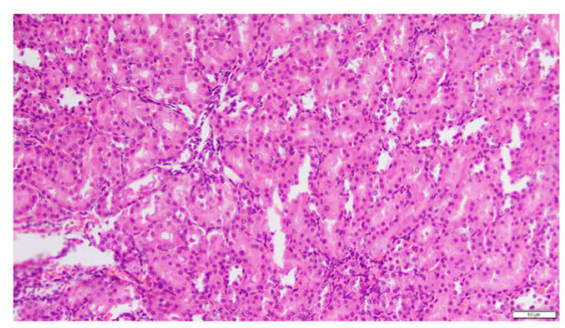

Rat $1-2000 \mathrm{mg} \mathrm{kg}^{-1}$ BW C. vulgaris

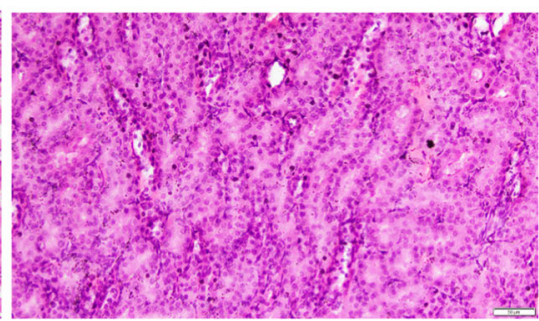

Rat 4 - $2000 \mathrm{mg} \mathrm{kg}^{-1} \mathrm{BW}$ C. vulgaris

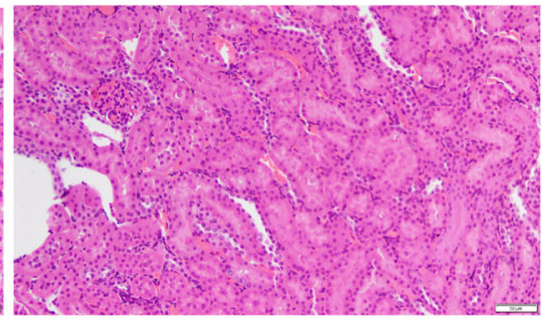

Rat 5 - $2000 \mathrm{mg} \mathrm{kg}^{-1} \mathrm{BW}$ C. vulgaris toxicity signs for doses exceeding the proposed carotenoid human-diet dose (de Mello-Sampayo et al. 2013). Other previous studies have reported the usage of $C$. vulgaris in mice and rats for up to $500 \mathrm{mg} \mathrm{kg}^{-1} \mathrm{BW}$ and $300 \mathrm{mg} \mathrm{kg}^{-1}$ BW of C. vulgaris, respectively (Dantas and Queiroz 1999; Ngah and Yusof 2006; Mukti et al. 2009). In a study performed on the determination of $C$. vulgaris in the treatment of diabetic Goto-Kakizaki (GK) rats, no significant differences were found in the plasma levels of AST and ALT, total protein and albumin concentration in normal Wistar rats treated with $3 \%$ and $5 \%(\mathrm{w} / \mathrm{w})$ of C. vulgaris for 8 weeks and in diabetic GK rats, suggesting that the different levels of $C$. vulgaris did not affect the animals' liver and heart function (Jeong et al. 2009). 
Fig. 6 Summary of the oral toxicity findings

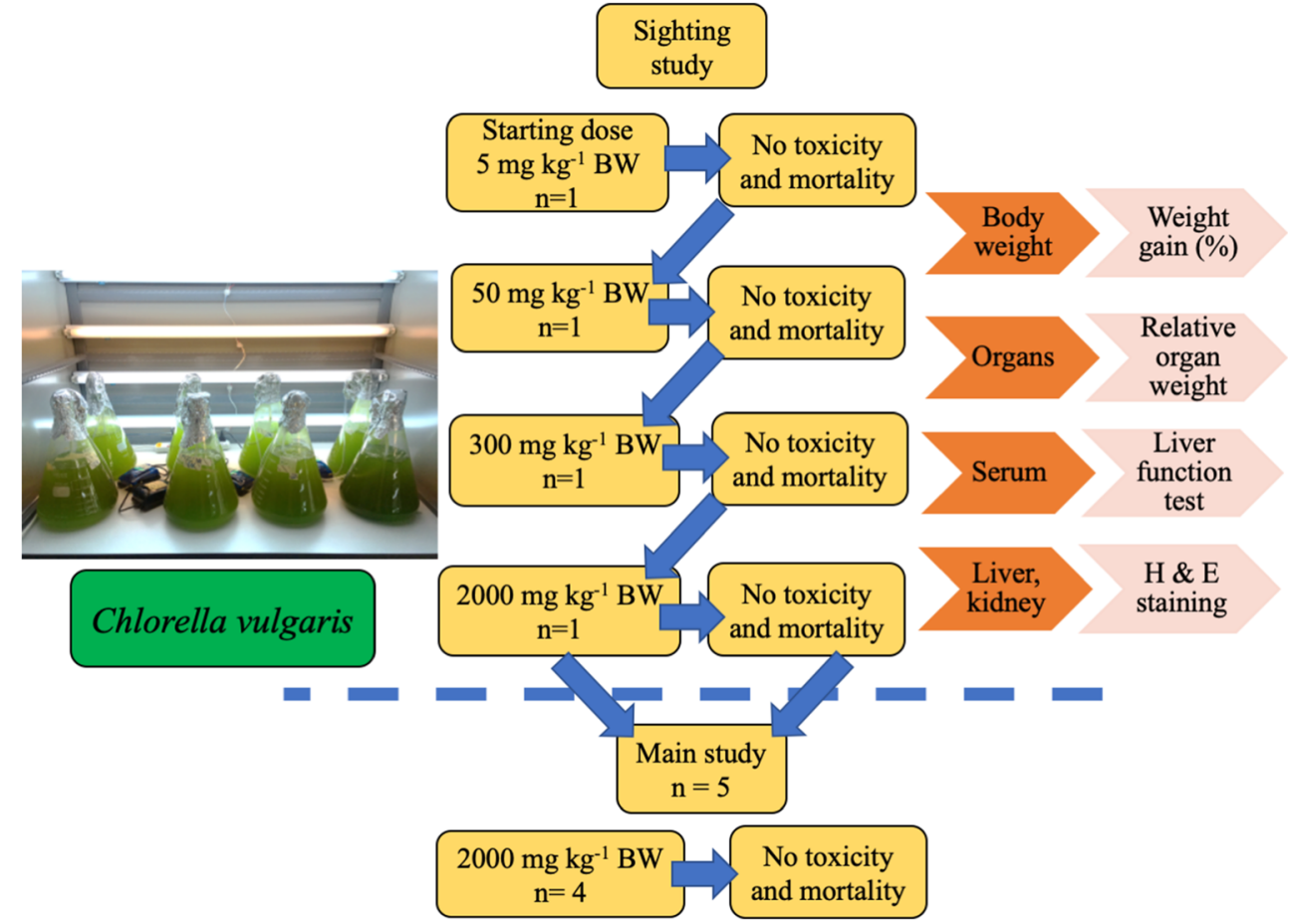

\section{Conclusion}

The varying dosages of $C$. vulgaris revealed no physical or behavioural changes, and no pain or distress occurred, indicating no toxicity of $C$. vulgaris. Chlorella vulgaris at $2000 \mathrm{mg} \mathrm{kg}^{-1}$ BW demonstrated no acute hepatotoxicity in female SD rats based on an acute oral toxicity study according to the OECD Guideline 420 . Hence, C. vulgaris can be categorized as unclassified under the classification of GHS. It is possible that the pharmacological effects that can be found in C. vulgaris are due to its naturally occurring components. Future studies on C. vulgaris should involve the identification and isolation of its active components and should further research its bioactivity.

Acknowledgements The authors are grateful to the University of Malaya Algae Culture Collection (UMACC, Malaysia) for supplying the stock of C. vulgaris. We are also thankful for the contribution from all researchers and staffs of the Department of Biochemistry and the Department of Anatomy, Faculty of Medicine, Universiti Kebangsaan Malaysia.

Author contributions Suzana Makpol and Yasmin Anum Mohd Yusof were responsible for the experimental design. Nurhazirah Zainul Azlan performed the experimentation as part of a $\mathrm{PhD}$ study, carried out the data analysis and prepared the manuscript. Norzana Abd Ghafar analysed the kidney and liver histology. Suzana Makpol supervised the work, interpreted the data and revised and amended the manuscript for publication. All authors read and approved the final manuscript.

Funding information This work was financially supported by the Ministry of Education (MOE) Malaysia (grant number FRGS/2/2014/ SKK01/UKM/01/1) and the Universiti Kebangsaan Malaysia (grant number UKM-FF-2016-318).
Data availability The raw data used to support the findings of the study are available from the corresponding author upon request.

\section{Compliance with ethical standards}

Conflict of interest The authors declare that they have no conflicts of interest.

Ethics approval This research was approved by the Universiti Kebangsaan Malaysia Medical Research and Innovation Secretariat with project code of FF-2016-318 and the Universiti Kebangsaan Malaysia Animal Ethics Committee (UKMAEC) with approval number BIOC/PP/2016/SUZANA/27-JULY/770-SEPT.-2016-AUG.-2018.

Open Access This article is licensed under a Creative Commons Attribution 4.0 International License, which permits use, sharing, adaptation, distribution and reproduction in any medium or format, as long as you give appropriate credit to the original author(s) and the source, provide a link to the Creative Commons licence, and indicate if changes were made. The images or other third party material in this article are included in the article's Creative Commons licence, unless indicated otherwise in a credit line to the material. If material is not included in the article's Creative Commons licence and your intended use is not permitted by statutory regulation or exceeds the permitted use, you will need to obtain permission directly from the copyright holder. To view a copy of this licence, visit http://creativecommons.org/licenses/by/4.0/.

\section{References}

Ahluwalia SS, Goyal D (2007) Microbial and plant derived biomass for removal of heavy metals from wastewater. Bioresour Technol 98: 2243-2257

Aizzat O, Yap SW, Sopiah H, Madiha MM, Hazreen M, Shailah A, Wan JWY, Nur SA, Das S, Musalmah M, Yusof YAM (2010) Modulation of oxidative stress by Chlorella vulgaris in 
streptozotocin (STZ) induced diabetic Sprague-Dawley rats. Adv Med Sci 55:281-288

Akhtar N, Saeed A, Iqbal M (2003) Chlorella sorokiniana immobilized on the biomatrix of vegetable sponge of Luffa cylindrica: a new system to remove cadmium from contaminated aqueous medium. Bioresour Technol 88:163-165

Aliahmat NS, Noor MRM, Yusof WJW, Makpol S, Ngah WZW, Yusof YAM (2012) Antioxidant enzyme activity and malondialdehyde levels can be modulated by Piper betle, tocotrienol rich fraction and Chlorella vulgaris in aging C57BL/6 mice. Clinics 67:14471454

Andersen RA, Berges JA, Harrisson PJ, Watanabe MM (2005) Recipes for freshwater and seawater media. In: Andersen RA (ed) Algal Culturing Techniques. Elsevier Academic Press, Amsterdam, pp $429-538$

Azamai ESM, Sulaiman S, Habib SHM, Looi ML, Das S, Hamid NAA, Ngah WZW, Yusof YAM (2009) Chlorella vulgaris triggers apoptosis in hepatocarcinogenesis-induced rats. J Zhejiang Uni Sci B 10:14-21

Bailey SA, Zidell RH, Perry RW (2004) Relationships between organ weight and body/brain weight in the rat: what is the best analytical endpoint? Toxicol Pathol 32:448-466

Bishop ML, Fody EP, Schoeff LE (2013) Clinical chemistry: principles, techniques, and correlations. Lippincott Williams \& Wilkins, Philadelphia

Boyer TD, Manns MP, Sanyal AJ (2012) Zakim and Boyer's hepatology. Elsevier Saunders, Philadelphia

Brennan L, Owende P (2010) Biofuels from microalgae - a review of technologies for production, processing, and extractions of biofuels and co-products. Renew Sust Energ Rev 14:557-577

Chatterjea MN, Chawla R (2010) Clinical chemistry (organ function tests, laboratory investigations and inborn metabolic diseases). Jaypee Brothers Medical Publishers, New Delhi

Dantas DC, Queiroz ML (1999) Effects of Chlorella vulgaris on bone marrow progenitor cells of mice infected with Listeria monocytogenes. Int J Immunopharmacol 21:499-508

de Mello-Sampayo C, Corvo ML, Mendes R, Duarte D, Lucas J, Pinto R, Batista AP, Raymundo A, Silva-Lima B, Bandarra NM, Gouveia L (2013) Insights on the safety of carotenogenic Chlorella vulgaris in rodents. Algal Res 2:409-415

de Melo RG, de Andrade AF, Bezerra RP, Marques DAV, da Silva VA, Paz ST, Filho JLL, Porto ALF (2019) Hydrogel-based Chlorella vulgaris extracts: a new topical formulation for wound healing treatment. J Appl Phycol 31:3653-3663

Ebrahimi-Mameghani M, Aliashrafi S, Javadzadeh Y, Asghari Jafarabadi M (2014) The effect of Chlorella vulgaris supplementation on liver enzymes, serum glucose and lipid profile in patients with nonalcoholic fatty liver disease. Health Promot Perspect 4:107-115

Gao C, Zhai Y, Ding Y, Wu Q (2010) Application of sweet sorghum for biodiesel production by heterotrophic microalga Chlorella protothecoides. Appl Energy 87:756-761

Garcia JL, de Vicente M, Galan B (2017) Microalgae, old sustainable food and fashion nutraceuticals. Microb Biotechnol 10:1017-1024

Griffiths MJ, Harrison ST (2009) Lipid productivity as a key characteristic for choosing algal species for biodiesel production. J Appl Phycol 21:493-507

Grobbelaar JU (2004) Algal nutrition-mineral nutrition. In: Richmond A (ed) Handbook of microalgal culture: biotechnology and applied phycology. Blackwell Science, Oxford, pp 95-115

Himuro S, Ueno S, Noguchi N, Uchikawa T, Watanabe K (2014) Safety evaluation of mutagenecity, acute and subacute toxicity study of Chlorella vulgaris CK-22 in rats. Fundam Toxicol Sci 1:151-159

Janczyk P, Wolf C, Souffrant WB (2005) Evaluation of nutritional value and safety of the green micro-algae Chlorella vulgaris treated with novel processing methods. Arch Zootech 8:132-147
Jeong H, Kwon HJ, Kim MK (2009) Hypoglycemic effect of Chlorella vulgaris intake in type 2 diabetic Goto-Kakizaki and normal Wistar rats. Nutr Res Pract 3:23-30

Johnston DE (1999) Special considerations in interpreting liver function tests. Am Fam Physician 59:2223-2230

Kitada K, Machmudah S, Sasaki M, Goto M, Nakashima Y, Kumamoto $\mathrm{S}$, Hasegawa $\mathrm{T}$ (2009) Supercritical $\mathrm{CO}_{2}$ extraction of pigment components with pharmaceutical importance from Chlorella vulgaris. J Chem Technol Biotechnol 84:657-661

Koyande AK, Chew KW, Rambabu K, Tao Y, Chu DT, Show PL (2019) Microalgae: a potential alternative to health supplementation for humans. Food Sci Human Wellness 8:16-24

Krienitz L, Huss VA, Bock C (2015) Chlorella: 125 years of the green survivalist. Trends Plant Sci 20:67-69

Lala V, Goyal A, Bansal P, Minter AD (2020) Liver function test. StatPearls Publishing LLC, Florida

Lordan S, Ross RP, Stanton C (2011) Marine bioactives as functional food ingredients: potential to reduce the incidence of chronic diseases. Mar Drugs 9:1056-1100

Makpol S, Yeoh TW, Ruslam FAC, Arifin KT, Yusof YAM (2013) Comparative effect of Piper betle, Chlorella vulgaris and tocotrienol-rich fraction on antioxidant enzymes activity in cellular ageing of human diploid fibroblasts. BMC Complem Altern Med 13:1-10

Masojídek J, Torzillo G (2008) Mass cultivation of freshwater microalgae. In: Jorgensen SE, Fath B (eds) Encyclopedia of ecology. Elsevier, Oxford, pp 2226-2235

Michael B, Yano B, Sellers RS, Perry R, Morton D, Roome N, Johnson JK, Schafer K (2007) Evaluation of organ weights for rodent and non-rodent toxicity studies: a review of regulatory guidelines and a survey of current practices. Toxicol Pathol 35:742-750

Mukti NA, Sulaiman S, Saad SM, Basari H (2009) Chlorella vulgaris menunjukkan kesan antioksidan dan antitumor terhadap kanser hepar dalam kajian in vivo dan in vitro. Sains Malays 38:773-784

Natrah F, Yusoff F, Shariff M, Abas F, Mariana N (2007) Screening of Malaysian indigenous microalgae for antioxidant properties and nutritional value. J Appl Phycol 19:711-718

Ngah WZW, Yusof YAM (2006) Chemo preventive effect of Chlorella vulgaris in choline deficient diet and ethionine induced liver carcinogenesis in rats. Int J Cancer Res 2:234-241

O'Connel TX, Horita TJ, Kasravi B (2005) Understanding and interpreting serum protein electrophoresis. Am Fam Physician 71: $105-112$

OECD (2001a) OECD Guideline for the testing of chemicals Organisation for Economic Co-operation and Development:1-14

OECD (2001b) OECD series on testing and assessment number 33. Organisation for Economic Co-operation and Development:1-247

Pagana KD, Pagana TJ (2010) Mosby's manual of diagnostic and laboratory tests, 4th edn. Elsevier, St. Louis

Panahi Y, Pishgoo B, Jalalian HR, Mohammadi E, Taghipour HR, Sahebkar A, Abolhasani E (2012) Investigation of the effects of Chlorella vulgaris as an adjunctive therapy for dyslipidemia: results of a randomised open-label clinical trial. Nutr Diet 69:13-19

Panahi Y, Mostafazadeh B, Abrishami A, Saadat A, Beiraghdar F, Tavana S, Pishgoo B, Parvin S, Sahebkar B (2013) Investigation of the effects of Chlorella vulgaris supplementation on the modulation of oxidative stress in apparently healthy smokers. Clin Lab 59: $579-587$

Phang SM (2010) Potential products from tropical algae and seaweeds, especially with reference to Malaysia. Mal J Sci 29:160-166

Rzymski P, Budzulak J, Niedzielski P, Klimaszyk P, Proch J, Kozak L, Poniedzialek L (2018) Essential and toxic elements in commercial microalgal food supplements. J Appl Phycol 31:3567-3579

Saad SM, Yusof YAM, Ngah WZW (2006) Comparison between locally produced Chlorella vulgaris and Chlorella vulgaris from Japan on 
proliferation and apoptosis of liver cancer cell line, HepG2. Malays J Biochem Molec Biol 13:32-36

Sharp PE, La Regina MC (1998) The laboratory rat. CRC Press, Boca Raton

Shibata S, Natori Y, Nishihara T, Tomisaka K, Matsumoto K, Sansawa H, Nguyen VC (2003) Antioxidant and anti-cataract effects of Chlorella on rats with streptozotocin-induced diabetes. J Nutr Sci Vitaminol 49:334-339

Suckow MA, Weisbroth SH, Franklin CL (2006) The laboratory rat. Elsevier Academic Press, Oxford

Vecina JF, Oliveira AG, Araujo TG, Baggio SR, Torello CO, Saad MJA, Queiroz MLS (2014) Chlorella modulates insulin signaling pathway and prevents high-fat diet-induced insulin resistance in mice. Life Sci 95:45-52

Wang HM, Pan JL, Chen CY, Chiu CC, Yang MH, Chang HW, Chang JS (2010) Identification of anti-lung cancer extract from Chlorella vulgaris $\mathrm{CC}$ by antioxidant property using supercritical carbon dioxide extraction. Process Biochem 45:1865-1872
Yadav MP, Rani K, Chauhan MK, Panwar A, Sandal N (2020) Evaluation of mercury adsorption and removal efficacy of pulverized Chlorella (C. vulgaris). J Appl Phycol 32:1253-1262

Yusof YAM, Saad SM, Makpol S, Shamaan NA, Ngah WZW (2010) Hot water extract of Chlorella vulgaris induced DNA damage and apoptosis. Clinics 65:1371-1377

Zainul Azlan N, Yusof YAM, Alias E, Makpol S (2019a) Chlorella vulgaris improves the regenerative capacity of young and senescent myoblasts and promotes muscle regeneration. Oxidative Med Cell Longev 2019:1-16

Zainul Azlan N, Yusof YAM, Alias E, Makpol S (2019b) Chlorella vulgaris modulates genes and muscle-specific microRNAs expression to promote myoblast differentiation in culture. Evid Based Complemen Altern Med 2019:1-16

Publisher's note Springer Nature remains neutral with regard to jurisdictional claims in published maps and institutional affiliations. 